\title{
Varying reinforcement frequency on a percentage-reinforcement schedule'
}

ALLEN J. NEURINGER, FOUNDATION FOR RESEARCH ON
THE NER VOUS SYSTEM, 36 The Fenway, Boston, Mass. 02215

Small fixed-interval components ended either with food or with an arbitrary stimulus. When the frequency of food was parametrically decreased under this "percentage-reinforcement" schedule, pigeons' rates of responding decreased but remained twice as high as the rates under control schedules having the same frequencies of food alone.

When only some of the intervals in a fixed-interval (FI) schedule of reinforcement terminate with food, while all other intervals terminate with an arbitrary stimulus, the resulting schedule is called a percentage-reinforcement (PR) schedule (Ferster \& Skinner, 1957). The rates and patterns of responding obtained are sometimes strikingly similar to those under a regular FI schedule in which every interval ends with food-even though the frequencies of food in the two cases are quite different (Neuringer \& Chung, 1967; Chung \& Neuringer, 1967). This experiment examines the possibly independent control exerted by food frequency and schedule components under a PR schedule.

Subjects. Six male White Carneaux pigeons were kept at $85 \%$ of their freefeeding weights.

Apparatus. A standard experimental chamber for pigeons, as described by Ferster \& Skinner (1957), was used. Reinforcement consisted of 3-sec access to grain.

Procedure. The Ss were arbitrarily divided into two groups of three, a percentage-reinforcement group (PR) and a variable-interval control group (VI). Under the percentage-reinforcement schedule, a response initiated a 5-sec fixed-interval component (tand FR 1 FI 5 -sec) which was terminated by either a response-produced food reinforcement or a response-produced 1-sec period of total darkness (1-sec blackout). During blackouts, pecks did not produce feedback clicks and were not recorded. Reinforcements were programmed by a variable-interval timer which was operated throughout the session except after it had primed and while reinforcements were presented. A 5-sec component ended with a reinforcement if the VI programmer had previously primed and with a blackout if the programmer had not primed. After either reinforcement or blackout, a response initiated another 5-sec interval. (See Neuringer \& Chung, 1967, for a more detailed description.) To ensure that the blackout intervals did not influence session time, the VI timer continued to operate during these intervals.

Under the control condition, reinforcements were programmed by the same variable-interval timer as above. However, under this condition, there were neither the 5-sec components nor the blackouts found under the PR condition. The first response to occur after the VI programmer had primed produced reinforcement. All other responses were followed only by feedback clicks.

The independent variable was the average interreinforcement interval, or the value of the VI. The VI values, in the order presented, were $1 / 2,1,2,4,8$, and $16 \mathrm{~min}$. To keep session length within manageable limits, the number of reinforcements per session were $30,30,30,15,15$, and 9 for each of the above VI conditions, respectively. Each condition was maintained for approximately 30 sessions. Following the VI $16 \mathrm{~min}$ condition, responding was extinguished, i. e., no primary reinforcements were presented. For the $P R$ group, blackouts continued to be presented according to the same tand FR 1 FI 5-sec schedule; for the control group, the only stimulus was a feedback click following each response. The birds were exposed to this condition for 17 sessions, each session lasting $1 \mathrm{~h}$.

Geometric averages of response rates over the last seven sessions at each condition were the basic measure of performance. For both groups, rates of responding were calculated by dividing the number of effective responses in a session by the total session time excluding only reinforcement time. Since, for the PR group, the VI timer was activated during the blackout intervals, these intervals were used in the response rate calculations. Including these intervals lowered response rates for the PR birds by no more than 10 responses per min.
Results. Figure 1 shows rates of responding as a function of VI value. Note that the logarithmic ordinate permits comparisons between the relative variabilities and the relative decrements in responding for each group. As average interreinforcement time increased from $1 / 2 \mathrm{~min}$ to $16 \mathrm{~min}$, response rates decreased similarly under both PR and control conditions. At all values, however, the $P R$ response rates were approximately twice as high as the control rates. Figure 2 shows the geometric average number of responses emitted each day under the two extinction conditions. After the first session, there was no appreciable difference between the PR and control groups.

Discussion. The enhanced responding under a percentage-reinforcement schedule might indicate that the arbitrary stimuli under such a schedule acquired "reinforcing" attributes (Neuringer \& Chung, 1967). Such an interpretation is analogous to that given for the increased rates of responding

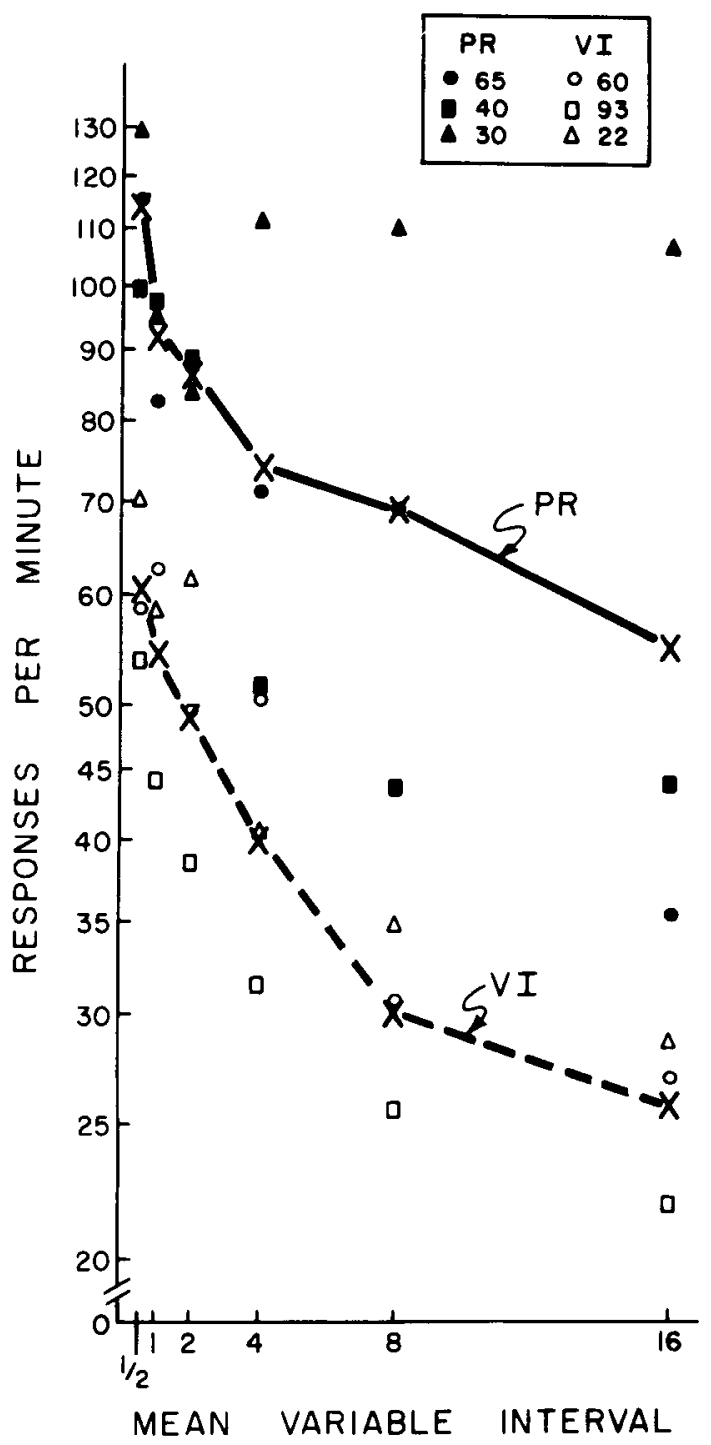

Fig. 1. Rates of responding under percentage-reinforcement (PR) and variable-interval control (VI) conditions as a function of average interreinforcement interval. The lines connect the geometric average performances of each group. 


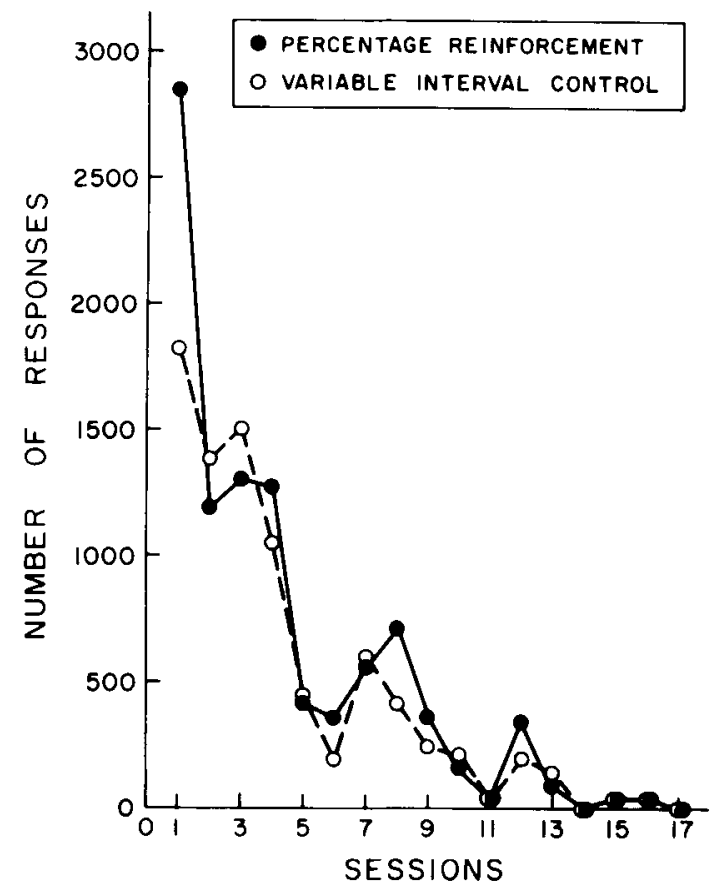

Fig. 2. Geometric average number of responses per session for each of 17 sessions of extinction.

caused by "secondary reinforcers" (Kelleher \& Gollub, 1962). However, the present results suggest an alternative interpretation. To a first order of approximation, the PR contingencies caused response rate to double, i.e., to increase by a multiplicative constant that was independent of the frequency of food. Thus, (a) decrements in response rate under both schedules were correlated with decrements in reinforcement frequency, and (b) the constant enhancement in responding found under the PR schedule was correlated with the constant 5-sec components superimposed under that schedule. Rate of responding might therefore be a joint function of (a) the frequency of food, and (b) the FI components, i.e., the percentage-reinforcement contingencies. Instead of hypothesizing that the blackouts under a PR schedule somehow become "reinforcing," we can more parsimoniously hypothesize that the PR contingencies themselves exert (nonreinforcing) control over responding. Note that the arbitrary stimuli are part of these contingencies and are necessary for the observed response increments (Neuringer \& Chung, 1967).

Other kinds of schedule contingencies, such as interval and ratio, are known to affect rates and patterns of responding independently of reinforcement frequency (Ferster \& Skinner, 1957). Furthermore, extinction following a high response rate is not necessarily more prolonged than that following a low response rate (Skinner, 1938). Such results parallel the present findings, and support the notion that the PR contingencies alone can account for the response rate enhancement. An analogous interpretation might explain the apparently similar effects produced by "secondary reinforcers."

\section{REFERENCES}

CHUNG, S. H., \& NEURINGER, A. J. Control of responding by a percentage reinforcement schedule. Psychon. Sci., 1967, 8, 25-26.

FERSTER, C. B., \& SKINNER, B. F. Schedules of reinforcement. New York: Appleton-Century-Crofts, 1957.

KELLEHER, R. T., \& GOLLUB, L. R. A review of positive conditioned reinforcement. J. exp. Anal. Behav., 1962, 5, 543-597.

NEURINGER, A. J., \& CHUNG, S. H. Quasi-reinforcement: control of responding by a percentage-reinforcement schedule. J. exp. Anal Behav., $1967,10,45-54$.

SKINNER, B. F. The behavior of organisms. New York: AppletonCentury-Crofts, 1938.

\section{NOTE}

1. This work was supported by grant MH 12108 from the National Institutes of Health. I wish to thank Dr. Shin-Ho Chung and Dr. Roger T. Kelleher for their advice, and Miss Maria Oliva and Miss Andrea Schein for their unfailing assistance. Reprints may be obtained from the author, Foundation for Research on the Nervous System, 36 The Fenway, Boston, Massachusetts 02215 . 